\title{
Legitimidad y posibilidad del pensamiento: Sobre dos modos de lectura según Gilles Deleuze
}

\author{
Legitimacy and possibility of thinking: On two ways \\ of reading proposed by Gilles Deleuze
}

GeRMÁn OSVALDO PRÓSPERI (Da

\section{Resumen}

En la famosa "Lettre à un critique sévère", Gilles Deleuze sugiere que existen dos maneras de leer un libro: una que supone un proceso de interpretación y comentario y otra que supone un proceso de experimentación y devenir. En este artículo nos proponemos mostrar que la primera modalidad de lectura es característica de la filosofía entendida como especialización, mientras que la segunda es característica de la filosofía entendida como experimentación. Asimismo, mostraremos que la primera modalidad obedece a un impulso retrospectivo mientras que la segunda a un impulso prospectivo.

Palabras clave: Lectura. Filosofía. Especialización. Historia de la Filosofía.

\begin{abstract}
Gilles Deleuze suggests in "Lettre à un critique sévère" that there are two ways of reading a book: one that includes a process of interpreting and annotating, and a second one that implies a process of becoming and experiencing. This article aims at demonstrating that the first way of reading is characteristic of philosophy regarded as specialization while the second way is characteristic of philosophy regarded as experimentation. Al the same time, we will prove that the first way of reading is guided by a retrospective impulse and the second one is guided by a prospective impulse.
\end{abstract}

Keywords: Reading. Philosophy. Specialization. History of Philosophy.

\footnotetext{
a Universidad Nacional de La Plata, Provincia de Buenos Aires, Argentina. Doctor en Filosofía, e-mail: gerprosperi@hotmail.com
} 
Es una moral de estado civil; ella rige nuestros documentos.

Que nos deje en paz cuando se trata de escribir.

M. Foucault, L'archéologie du savoir

\section{Introducción}

En la famosa "Lettre à un critique sévère", Gilles Deleuze sugiere, casi de pasada, que existen dos maneras de leer un libro: una según la cual se lo considera como un continente que remite a un contenido cuyos significados deben ser oportunamente descifrados, otra según la cual se lo considera como una máquina asignificante cuyo único problema es si funciona o no funciona (cfr. 1990, p. 17). La primera modalidad de lectura supone un proceso de interpretación; la segunda, un proceso de experimentación. Mientras que la primera forma de leer da lugar a objeciones y comentarios: "Se comentará, se interpretará, se pedirán explicaciones, se escribirá el libro del libro, hasta el infinito” (cfr. 1990, p. 17), la segunda da lugar a un devenir intensivo: "Esta otra lectura lo es en intensidad: algo pasa o no pasa. No hay nada que explicar, nada que interpretar, nada que comprender" (1990, p. 17). ${ }^{1}$ Por supuesto que es preciso matizar estas afirmaciones de Deleuze pero sin dejar de lado su intención profunda. No se trata de que la lectura de un texto no suponga un trabajo hermenéutico - como el que el propio filósofo ha realizado, y con suficiente rigor, en relación a las obras de Hume, Spinoza, Bergson, Nietzsche, Foucault o Leibniz -; ${ }^{2}$ no se trata tampoco de que los escritos filosóficos no puedan ser criticados - como, de nuevo, ha hecho el mismo Deleuze en relación a Descartes, Hegel o Freud -.; 3 se trata,

\footnotetext{
1 La misma idea se encuentra en "Rhizome": "Nunca hay que preguntar qué quiere decir un libro [...], tan sólo hay que preguntarse con qué funciona" (1980, p. 10). Este ensayo, que por otro lado oficia de introducción a Mille plateaux, desarrolla las diferentes concepciones tradicionales del libro y a la vez la concepción maquínica que proponen Deleuze y Guattari. ${ }^{2}$ La bibliografía sobre el pensamiento de Deleuze es vastísima y no vale la pena consignarla aquí. No obstante, sobre su primera época, dedicada preferentemente a trabajos monográficos sobre autores diversos, cfr. Mengue, 1994. Es preciso indicar, sin embargo, que Deleuze no abandonó nunca, al menos hasta 1988, su costumbre de escribir libros sobre otros autores. En efecto, Le Pli. Leibniz et le barroque es de 1988, dos años posterior a su texto sobre Foucault.

${ }^{3}$ Leemos en Dialogues: "No soportaba ni a Descartes, los dualismos y el Cogito, ni a Hegel, las tríadas y el trabajo de lo negativo" (1996, p. 21); o también, esta vez en Pourparlers: "Lo que yo más detestaba era el hegelianismo y la dialéctica" (1990, p. 14). Sobre las críticas a
} 
más bien, de prestar atención a las posibilidades de pensamiento que un texto es capaz de abrir y no tanto a la legitimidad - que siempre adolece de un cierto tono moral y judicial - de esas posibilidades.

Ahora bien, nos interesa detenernos en estas indicaciones de Deleuze, no sólo porque atañen específicamente a la lectura, ${ }^{4}$ sino porque permiten comprender con mayor claridad, creemos, los dos grandes modos de leer que imperan hoy en el ambiente filosófico (sobre todo académico). En este sentido, el objetivo del presente artículo consistirá en mostrar que la primera modalidad de lectura es característica de las evaluaciones académicas y de la filosofía entendida como especialización y profesionalización $;^{5}$ la segunda modalidad, en cambio, es característica de la filosofía entendida como experimentación y devenir. ${ }^{6}$ No vale la pena aclarar que para Deleuze y también para nosotros, por cierto - sólo esta última forma de lectura es propiamente filosófica. Para demostrar este punto será preciso explicar en detalle la naturaleza de ambas modalidades, meramente esbozadas por Deleuze en su carta, identificando además a la primera, inescindible de la mala conciencia y el resentimiento, con una

Freud y Lacan, sobre todo a la negatividad del deseo, cfr. Deleuze y Guattari, 1972; Deleuze, 1996, pp. 95-145.

${ }^{4}$ En efecto, el tópico de la lectura ha sido mucho menos trabajado por el propio Deleuze y por sus comentadores que el tópico de la escritura. Todo Critique et clinique (1993), por ejemplo, está dedicado al problema de la escritura, al igual que el texto sobre Proust (1964) y sobre Kafka (1975). No sería arriesgado decir que la cuestión de la escritura, en cierto sentido, atraviesa prácticamente la totalidad de la obra deleuziana. Para un panorama general del problema de la lectura desde una perspectiva histórica, cfr. Chartier y Cavallo, 1997.

5 Pierre Hadot ha demostrado, con absoluta contundencia, cómo la filosofía, de ser una forma de vida, ha pasado a ser una profesión académica muchas veces inerte. Citamos un pasaje iluminador: "la institución universitaria conduce a hacer del profesor de filosofía un funcionario cuya tarea consiste, en gran parte, en formar a otros funcionarios; no se trata ya, como en la Antigüedad, de formar en el oficio de hombre, sino de formar en el oficio de clérigo o de profesor, es decir, de especialista, de teórico, detentor de un cierto saber, más o menos esotérico. Pero este saber no pone más en juego toda la vida, como lo quería la filosofía antigua" (1995, p. 390-391).

${ }^{6}$ Según Deleuze y Guattari, la filosofía se caracteriza básicamente por la creación de conceptos: "La filosofía, con mayor rigor, es la disciplina que consiste en crear conceptos. [...] Crear conceptos siempre nuevos, tal es el objeto de la filosofía" (Deleuze y Guattari, 2005, p. 10). Por otra parte, todo "concepto tiene un devenir que atañe en este caso a unos conceptos que se sitúan en el mismo plano" (2005, p. 23). De más está decir que para Deleuze el devenir de la filosofía no coincide con su historia, más bien se le opone: "Hay un devenir-filósofo que no tiene nada que ver con la historia de la filosofía, y que pasa más bien por todos aquellos que la historia de la filosofía no logra clasificar" (1996, p. 8). 
forma reactiva de lectura, y a la segunda, inescindible de las líneas de fuga y los devenires, con una forma activa. ${ }^{7}$ Propondremos, retomando una sugerencia deleuziana, que la primera modalidad es cuantitativa o extensiva mientras que la segunda es cualitativa o intensiva. Asimismo, mostraremos, introduciendo un punto no desarrollado por Deleuze, que la primera modalidad obedece a un impulso retrospectivo mientras que la segunda a un impulso prospectivo. Adviértase, por otro lado, que el panorama que resulta de este análisis no deja de ser desolador: si la lectura académica dominante, encarnada de manera eminente en la figura del especialista, coincide con la primera modalidad, y si ésta es generalmente reactiva, entonces la lectura académica es generalmente reactiva. ${ }^{8}$

Aclaramos, por último, que la identificación de la lectura reactiva con la figura del especialista que proponemos aquí no responde a un capricho nuestro sino a una idea deleuziana. La historia de la filosofía, para Deleuze, ha sido siempre una máquina de producir especialistas del pensamiento. Considérese, a modo de ejemplo, el siguiente pasaje:

La historia de la filosofía ha sido siempre el agente de poder en la filosofía e incluso en el pensamiento. Ella juega el rol de represor: ¿cómo queréis pensar sin haber leído a Platón, Descartes, Kant y Heidegger y el libro de tal y tal sobre ellos? Una formidable escuela de intimidación que fabrica especialistas del pensamiento [spécialistes de la pensée] (DELEUZE, 1996, pp. 19-20).

Se advertirá la dificultad, y en cierto sentido la paradoja, sobre la que se sostiene este artículo. Se trata de abordar un problema filosófico, en este caso la crítica deleuziana a la filosofía entendida como especialización y por ende a los artículos especializados, en un formato (el de artículo especializado, precisamente) que resulta

\footnotetext{
${ }^{7}$ Deleuze retoma la distinción entre lo activo y lo reactivo de la filosofía de Nietzsche (cfr., en particular, Deleuze, 1962, pp. 44-82). Explicaremos ambos conceptos, y su relación con las dos formas de lectura propuestas en este artículo, en el apartado 2.

8 Decimos "generalmente" porque se trata de una tendencia y no de una determinación fatalista e inexorable. Por eso mismo, nuestro artículo no pretende decir que todos los especialistas efectúan una lectura reactiva, lo cual sería sin duda falso, de la misma manera que no pretende decir que todos los no especialistas efectúan una lectura activa, lo cual sería igualmente falso, sino más bien señalar una cierta tendencia a la reactividad en la práctica especializada, es decir una cierta afinidad entre la especialización o profesionalización de la filosofía y la reactividad en su sentido nietzscheano.
} 
deconstruido por el ejercicio mismo de esa crítica. En cierta forma, el objetivo de este artículo es su propia refutación: su impugnación intrínseca. En una entrevista con Raymond Bellour y François Ewald, publicada en el Magazine littéraire en 1983, Deleuze decía que no se trata de "repetir lo que dijo un filósofo, sino de decir lo que él suponía necesariamente, lo que no dijo y sin embargo está necesariamente presente en lo que dijo" (1990, p. 186). Encontramos la misma idea, esta vez en la "Lettre à un critique sévère", cuando Deleuze sostiene que escribir sobre un filósofo supone crearle una suerte de hijo monstruoso:

Imaginaba llegar por la espalda de un autor, y hacerle un niño, que sería el suyo y sin embargo monstruoso. Era muy importante que sea el suyo, puesto que resultaba esencial que el autor diga todo lo que yo le hacía decir. Pero también era importante que el niño sea monstruoso, puesto que resultaba esencial pasar por toda clase de descentramientos, deslizamientos, robos, emisiones secretas que me han dado mucho placer (1990, p. 15).

Diríamos entonces que se trata aquí de hacerle un hijo monstruoso a Deleuze, pero un hijo monstruoso que sea sin embargo el suyo.

\section{La lectura especializada}

Expliquemos esta primera forma de lectura a partir de un ejemplo. Supongamos que un especialista debe leer un artículo en el que se retoma un concepto de - pongamos por caso - Lucrecio y se lo utiliza para pensar un problema completamente anacrónico y ajeno a la filosofía lucreciana. Supongamos además que ese concepto es el de clinamen (desvío o declinación de los átomos) y que se lo usa para pensar el problema de las dimensiones múltiples en una novela de ciencia ficción escrita por - también pongamos por caso - William Gibson. El especialista en Lucrecio, habituado a fatigosas jornadas de exégesis latina, sentirá sin duda una cierta desconfianza frente al uso - habría que decir quizás la profanación, el ab-usus - que este hipotético autor pretende hacer del concepto lucreciano. Su "buena" conciencia, sin embargo, lo obligará a leer el texto. Le bastará llegar a la mitad para formular la primera objeción, la más obvia: el autor no "problematiza" el concepto de clinamen al interior del De rerum natura. Pero ¿qué significa, para el especialista, "problematizar" 
un concepto? Significa, entre otras cosas, indicar los diferentes lugares textuales en los que Lucrecio utiliza el término y los sutiles matices, muchas veces microscópicos, que adquiere en contextos diversos. Significa también explicar por qué Lucrecio decide hacer uso de ese término, a qué problemas supuestamente intenta responder, qué influencias pueden haber contribuido a la acuñación de ese concepto, cuál es el aporte de esa noción a la tradición del materialismo epicúreo, etc. Significa, por último, demostrar un conocimiento acabado de los extensos debates a los que ha dado lugar el concepto, es decir de los innúmeros papers que han escrito especialistas reconocidos, como el que está leyendo en ese momento el presunto artículo, acerca de las también innúmeras interpretaciones del término. En suma, "problematizar" el concepto de clinamen significa, para el especialista, certificar que quien escribe el artículo es también - o casi - un especialista en Lucrecio.

Lo primero que quisiéramos decir es que esta idea de "problema" es absolutamente pobre. En efecto, problematizar no es demostrar que uno sabe, sino abrir - o, por lo pronto, situarse en - un espacio de pensamiento, espacio que no necesariamente tiene que estar contenido en el texto del cual se extrae el concepto. ${ }^{9}$ Lo curioso es que este uso o este desplazamiento - este clinamen, nótese la ironía - de

\footnotetext{
${ }^{9}$ En este punto, Deleuze recupera toda una tradición de la filosofía como ciencia de los problemas que incluye a Platón, Kant, Bergson, Lautman, Simondon, etc. En la novena serie de Logique du sens, titulada precisamente "Du problématique", Deleuze aborda los problemas, en una clara perspectiva simondoniana, en clave ontogenética. Los problemas conciernen a lo virtual o ideal, es decir a una realidad objetiva independiente de sus eventuales actualizaciones en una o más soluciones. Cada problema abre un espacio virtual sobre el cual se distribuyen elementos heterogéneos, intensidades o singularidades. Esta teoría topológica de los problemas - y recordemos la segunda sección del texto sobre Foucault titulada, no por casualidad, Topologie: 'penser autrement' - determina las condiciones trascendentales del pensamiento. No sólo el pensamiento es un asunto temporal, sino también topológico. Pensar no es una cuestión que concierne al sujeto y al objeto, sino al espacio y a los territorios. La filosofía, leemos en Qu'est-ce que la philosophie?, es fundamentalmente una geofilosofía. Los problemas (las Ideas), en este sentido, designan lugares metafísicos de pensamiento, regiones o planos inmanentes en los que se distribuyen los elementos singulares. En la concepción deleuziana de las Ideas-problemas existe, como bien nota James Williams, una clara preeminencia de los problemas sobre las soluciones, es decir de lo virtual sobre lo actual: "A su vez, Deleuze define las Ideas como problemas y como insuperablemente problemáticas, en el sentido de que no proporcionan soluciones absolutas y definitivas sino soluciones parciales que plantean el problema desde una nueva perspectiva" (WILLIAMS, 2003, p. 140). No es necesario aclarar que esta concepción de los problemas como territorios virtuales de pensamiento torna irrisorio cualquier intento por convertir a las ideas y los conceptos en propiedad privada. En efecto, el espacio del pensamiento, como han sabido los averroístas, es común a todos los hombres.
} 
un concepto propuesto por un autor latino casi contemporáneo a Cristo a un registro ficcional propio de un género literario relativamente reciente es precisamente el núcleo del artículo escrito por el hipotético autor. El especialista se detendrá en la legitimidad del uso y del desplazamiento. Por eso su lectura tendrá inexorablemente un cariz moral y judicial. Si además es miserable, de todas las interpretaciones posibles elegirá la más maliciosa. Recordemos las palabras de Deleuze a Michel Cressole, su crítico severo: "De todas las interpretaciones posibles, escoges casi siempre la más malvada o la más ruin" (1990, p. 12). De allí surgirá la segunda crítica: no hay bibliografía actualizada. Lo cual supone desconocer que la temporalidad de la filosofía no pertenece a la cronología. ${ }^{10}$ Las críticas de Aristóteles a Platón, en este sentido, no son menos "actuales" que las de un especialista contemporáneo en filosofía antigua. De la misma manera, un artículo escrito por un autor del siglo XIX sobre Lucrecio puede ser tan inspirador o interesante como uno escrito el día de ayer. ${ }^{11}$

Ahora bien, esta forma de lectura, sugerimos en la introducción, es de naturaleza retrospectiva. ¿Por qué? Porque el especialista mira hacia el pasado, en este caso hacia el De rerum natura - y, más allá, hacia Epicuro y los atomistas -, a fin de sopesar la legitimidad del uso del concepto que se propone en el hipotético artículo. Lo importante, para él, está siempre en la fuente, en la pureza del origen. ${ }^{12}$ Su mirada

\footnotetext{
${ }^{10}$ Para una distinción entre Cronos, el tiempo propio de la historia de la filosofía, y Aión, el tiempo propio de los acontecimientos y de la filosofía como devenir, cfr. Deleuze, 1969, pp. 190-197.

${ }^{11}$ Por razones de extensión, consideramos aquí sólo estos dos aspectos de la lectura especializada: la problematización de los conceptos y la actualidad de la bibliografía, dejando de lado otros factores igualmente importantes (y cuestionables): metodología, "aportes" posibles al área de estudio, coherencia entre el tema tratado y la metodología, claridad de objetivos, etc.

12 En 1971, Michel Foucault publica un ensayo titulado "Nietzsche, la généalogie, I'histoire" en el cual, entre otras cosas, opone el método genealógico "a la búsqueda del origen" (1994, p. 137). El genealogista rechaza la idea de origen (Ursprung), rechaza buscar en el pasado la verdad oculta, eternamente inmutable, del presente. Se ha creído encontrar en el origen de los fenómenos su verdad desnuda, su esencia inalterable, la llave que debería revelarnos, más allá de la contingencia y los avatares del tiempo, lo que las cosas son en sí mismas. A esta concepción reactiva de la historia, Foucault le opone la atención minuciosa a la singularidad de los acontecimientos, a las reglas contingentes de su dispersión, a la accidentalidad de su emergencia en un campo de fuerzas. En síntesis: la genealogía descubre que detrás de las cosas no existe ninguna verdad esencial, sino algo muy diferente (la cita es de Nietzsche y corresponde al \$123 de Morgenröthe): "en absoluto su secreto esencial y sin fechas, sino el secreto de que ellas están sin esencia, o que su esencia fue construida pieza por pieza a partir de figuras que le eran extrañas" (FOUCAULT, 1994, p. 138).
} 
es sólo sensible a la distancia que toma el autor del artículo respecto a Lucrecio. (¿Es posible esa lectura?, ¿no se contradice con otros pasajes del mismo texto?, ¿no formula tesis demasiado generales?, etc.). Se trata de una lectura extensiva-puesto que importa cuánto sabe el autor del artículo - y retrospectiva - puesto que se encuentra en el pasado, en el texto de origen, el criterio para llevar adelante la lectura. El especialista lee siempre mirando hacia atrás.

\section{La lectura filosófica}

Supongamos ahora que el mismo texto se encuentra frente a los ojos de un filósofo. La desconfianza del especialista ante la relación anacrónica que propone el artículo se traduce en interés por parte del filósofo. El nexo desconcertante entre un autor antiguo y un escritor contemporáneo de ciencia ficción genera una expectativa en el filósofo directamente proporcional a la desconfianza del especialista. ¿Por qué? Porque el filósofo está interesado en el pensamiento y no en su legitimidad, es decir en las posibilidades conceptuales que alberga, de forma más o menos latente, la noción de clinamen (en este caso) que en la mayor o menor fidelidad a Lucrecio. Si el especialista lee con la mirada hacia atrás, el filósofo lo hace con la mirada hacia adelante. Son como el Alfa y el Omega. Aquél es juez, éste cómplice; aquél es león, éste niño; aquél dicta sentencias, éste juega a los dados ${ }^{13}$.

Se comprenderá entonces por qué la lectura filosófica es intensiva - puesto que se demora en las intensidades que el texto permite experimentar - y prospectiva - puesto que apunta siempre a las posibilidades ${ }^{14}$ que el texto abre y no a la legitimidad que lo

\footnotetext{
${ }^{13}$ Las figuras del león y del niño, así como la del juego, remiten por supuesto al opúsculo "Von den drei Verwandlungen" de Also sprach Zarathustra. Al "no" destructor del león, le sucede el "sí" lúdico y creador del niño: "Inocencia es el niño, y olvido, un nuevo comienzo, un juego, una rueda que se mueve por sí misma, un primer movimiento, un santo decir sí. Sí, hermanos míos, para el juego del crear se precisa un santo decir sí" (Nietzsche, eKGWB/Za-I-Verwandlungen).

${ }^{14}$ El existencialismo ha mostrado la relación que existe entre la posibilidad y el futuro (proyecto). En Sein und Zeit, en efecto, Heidegger consigna: "El 'ser ahí' es en cada caso su posibilidad [seine Möglichkeit]" (1977, p. 57); razón por la cual, "a la constitución del ser del 'ser-ahí es inherente la pro-yección" (1977, p. 293). Sartre, por su parte, define también al hombre, en tanto posibilidad abierta, como un proyecto: "el hombre empieza por ser algo que se lanza hacia un porvenir [...]. El hombre es ante todo un proyecto" (1980, p. 34). No
} 
ha hecho posible. No se interesa tanto por las causas cuanto por los efectos. Qué efecto tiene en el pensamiento el uso que se propone de un concepto, qué permite pensar, qué caminos abre, qué espacios virtuales permite recorrer. Estas son las cuestiones que interesan al filósofo.

Por supuesto que se trata aquí de retratos ideales y, en consecuencia, exagerados. Estas dos figuras o arquetipos, el especialista y el filósofo, nunca se dan de forma pura. Nosotros las describimos de esa manera para resaltar los puntos en los que divergen. ${ }^{15}$ Muchos filósofos, de hecho, poseen un gran conocimiento de historia de la filosofía; muchos, incluso, son grandes especialistas. Lo que queremos decir es que no es ese conocimiento especializado el que los vuelve filósofos, sino el amor al pensamiento y el horror a la judicialización y a la moralización de la filosofía. Cada figura por eso mismo encarna una tendencia, un vector de lectura. Ambas interpretan, evalúan, juzgan incluso; pero el sentido de estas actividades en una y otra es por completo diferente. El conatus del filósofo, lo que lo impulsa a la lectura, es la posibilidad de pensamiento; el del especialista, su legitimidad. Si el filósofo está obsesionado con la potencia, el especialista lo está con la ley. El filósofo se pregunta: ¿qué me permite pensar este uso del clinamen que se me propone aquí?; el especialista, en cambio: ¿es legítimo este uso del clinamen que se me propone aquí? Lo cual no significa que el filósofo no pueda formularse preguntas acerca de la legitimidad o no de un uso conceptual, pero siempre estas preguntas estarán supeditadas a la primacía de la pregunta por la posibilidad de pensamiento que ese uso implica. Por eso las objeciones son siempre secundarias para el filósofo y son siempre primarias para el especialista. Al inicio de Dialogues, Deleuze sostiene: "Cada vez que se me hace una objeción me dan ganas de decir: 'De acuerdo,

obstante, es preciso aclarar que esta apelación a Heidegger y Sartre no significa que adoptemos aquí la concepción existencialista del hombre como proyecto, la cual ha sido criticada, y con justa razón, desde diversas perspectivas. Nuestra intención, más bien, es señalar simplemente la relación que existe entre la lectura prospectiva del filósofo y la posibilidad del pensamiento.

${ }^{15}$ En efecto, es posible que un especialista pueda verse atravesado por un devenir-filósofo, así como un filósofo por un devenir-especialista. No se trata, por eso, de figuras estáticas, sino de posiciones o funciones que pueden ser ocupadas o actualizadas por los mismos sujetos de forma alternativa. De todas maneras, como hemos indicado al inicio, nos parece detectar una cierta afinidad entre la filosofía entendida como especialización y la reactividad y filosofía entendida como experimentación y la actividad. El planteo de este artículo, por eso mismo, no alude a personas concretas, lo cual carecería del menor interés, sino a funciones o posiciones "ideales" encarnadas en las dos figuras mencionadas. 
de acuerdo, pero pasemos a otra cosa'. Las objeciones nunca han aportado nada" (1996, p. 7). La objeción apunta siempre a la legitimidad de un uso, y por eso conserva irremediablemente un cierto resabio moral y judicial. La graciosa expresión de Deleuze passons à autre chose indica la necesidad, para el filósofo, de atender a la posibilidad de pensamiento que alberga un concepto. No obstante, es preciso subrayar que el mismo Deleuze, como dijimos en la introducción, ha sido muy crítico respecto a ciertas corrientes filosóficas, por ejemplo el hegelianismo, la fenomenología o el psicoanálisis. Pero el punto no está en la objeción en cuanto tal, sino en la finalidad de la misma. El único sentido de una objeción o una crítica es la posibilidad de pensamiento que abre. Criticar un pensamiento sirve si y sólo si esa crítica permite considerar el problema desde otra perspectiva, es decir si funciona como condición de posibilidad de una nueva manera de pensar un asunto. Esto significa que las objeciones sólo resultan interesantes cuando funcionan como medios para un fin que es siempre, según la expresión de Foucault, pensar de otro modo ${ }^{16}$. En cambio, cuando las objeciones se vuelven un fin en sí mismas, la filosofía está perdida. Por eso suele ser más interesante, para un filósofo, la filosofía de la historia que la historia de la filosofía. No porque no haya historiadores excepcionales, capaces de formular pensamientos filosóficos con pleno derecho, tampoco porque la historia de la filosofía no constituya en sí misma una cantera riquísima de conceptos y pensamientos, sino porque la concepción meramente histórica de la filosofía - al menos tal como suele funcionar en el mundus academicus (o, por lo pronto, en los criterios que rigen las evaluaciones) - obedece en general a patrones cuantitativos: quien más sabe más vale ${ }^{17}$. Existe una especie de Tribunal de la razón

\footnotetext{
${ }^{16}$ Sería preciso leer en esta clave las extraordinarias páginas de la introducción a L'usage des plaisirs en las que Foucault explica que los motivos que lo impulsaron a modificar el programa inicial de la Histoire de la sexualité se debieron, en su raíz profunda, a un esfuerzo por "pensar distinto de como se piensa y percibir distinto de como se ve" (1984, p. 9). El saber no valdría nada, sostiene allí Foucault, "si sólo hubiera de asegurar la adquisición de conocimientos y no, en cierto modo y hasta donde se puede, el extravío del que conoce [l'égarement de celui qui connaît]" (1984, p. 9). La lectura filosófica, entendida como experimentación y devenir, no es otra cosa que este extravío. Por eso la filosofía no consiste para Foucault en "legitimar lo que ya se sabe", que es lo propio de los especialistas y profesionales, sino en "una ascesis, un ejercicio de sí, en el pensamiento" (1984, p. 9).

17 Sería interesante poner en relación este devenir-cuantitativo de la especialización académica con las investigaciones culturales de René Guénon, también conocido como Abd al-Wāhid Yahyá luego de su iniciación en el esoterismo islámico. En su texto Le règne de la quantité et les signes des temps, por ejemplo, Guénon sostiene que vivimos en un mundo "en
} 
académica que funciona muchas veces como un campo de concentración del pensamiento. Deleuze decía pertenecer, en este sentido, “a una de las últimas generaciones que han sido más o menos asesinadas por la historia de la filosofía" debido a que esa historia "ejerce, en el seno de la filosofía, una evidente función represiva" (1990, p. 14). Esta función represiva del aparato institucional o profesional de la filosofía constituye el aspecto reactivo del pensamiento. Como hemos indicado previamente, la lectura especializada o profesional posee un carácter reactivo, a diferencia de la lectura propiamente filosófica cuya naturaleza es esencialmente activa. Esta distinción entre lo activo y lo reactivo, también dijimos, proviene de Nietzsche. En su texto de 1962 sobre la filosofía nietzscheana, Deleuze explica que las fuerzas activas son aquellas que colman su potencia, es decir que van hasta el final de lo que pueden o de lo que son capaces. Estas fuerzas, por eso mismo, hacen "de su diferencia un objeto de placer y de afirmación" (DELEUZE, 1962, p. 69). Las fuerzas reactivas, por el contrario, operan de una manera completamente diferente: separan a las fuerzas activas de lo que éstas pueden, son fuerzas utilitarias que niegan a las activas y de esa negación obtienen su poder (cfr. 1962, p. 64, 69). Ahora bien, la lectura retrospectiva del especialista, que según Deleuze busca siempre un significado por descifrar y una objeción por formular, encarna esta función reactiva de la lectura. Represión y reacción, desde luego, van de la mano. El ojo del especialista, que es a su manera un juez y un fiscal, se demora siempre en los aspectos que para un filósofo son secundarios o nimios ("De acuerdo, de acuerdo, pero pasemos a otra cosa"). La función represiva de la institución profesional de la filosofía, tal como Deleuze la entiende, consiste en separar al pensamiento de lo que puede, sustraerle su potencia activa a fin de que no desarrolle todas las posibilidades de las que es capaz. Por eso Deleuze identifica al crítico severo con las figuras de la "mala conciencia" y del "resentimiento" que, en la perspectiva de Nietzsche, son paradigmáticas de la reactividad. Esta fonction répressive que encarna la academia filosófica $^{18}$ se evidencia en lo que podríamos llamar la Stimmung de la lectura:

el cual todas las cosas deben tomar un aspecto cada vez menos cualitativo y cada vez más cuantitativo; y es por eso que el último período del ciclo [es decir nuestro tiempo] debe tender a afirmarse como el 'reino de la cantidad'"' (1945, p. 64).

${ }^{18}$ Sin embargo, no debe creerse que este ideal policial forma parte exclusivamente de las prácticas académicas. Incluso los movimientos en apariencia más deconstructivos y transversales suelen adoptar formas policiales de control. La "policía del pensamiento" 
el especialista está siempre dispuesto a encontrar el punto débil, la contradicción, la ilegitimidad del argumento (el resentimiento como Stimmung); el filósofo, en cambio, está siempre dispuesto a seguir alegremente el flujo del texto, sin importarle demasiado de dónde proviene y sin saber a ciencia cierta a dónde conduce (la jovialidad como Stimmung ${ }^{19}$. Podría decirse que el especialista ensaya una lectura arqueológica: le interesa lo que ha hecho posible el texto que está leyendo, la arche, el origen que legitima el texto presente ${ }^{20}$ el filósofo, por el contrario, ensaya más bien una lectura profética: le interesa el lugar al cual se dirige - o, mejor aún, puede dirigirse - el pensamiento, el horizonte imprevisible al que lo orienta una propensión que no implica meta o finalidad sino apertura y azar. De allí que sea una posibilidad y no un destino: "Un pensamiento que fuese al final de lo que puede la vida, un pensamiento que llevase a la vida hasta el final de lo que puede. [...] Pensar significaría: descubrir, inventar nuevas posibilidades de vida" (DELEUZE, 1962, p. 115; el subrayado es de Deleuze). Como hemos dicho, el filósofo se apega siempre a la posibilidad que el pensamiento alberga y no, como el especialista, a su legitimidad. No es por eso un sacerdote, diríamos que está más cerca de ser un artista, un idiota o un demente.

Mientras que la lectura arqueológica del especialista se pregunta por las condiciones de posibilidad del texto que está leyendo, la lectura profética del filósofo se pregunta por las posibilidades que el texto abre. Aquélla se remonta al pasado que ha hecho posible al texto en cuestión, ésta al futuro que el texto hace posible. Uno lo considera a posteriori y su lectura consiste en remontarse a sus condiciones pasadas de posibilidad (su a priori pretérito); el otro, lo considera a priori y su lectura consiste en proyectarse a las posibilidades futuras de pensamiento (su a posteriori venidero).

(Thought Police), según la famosa fórmula de Georges Orwell (1949), opera en todos los niveles del campo social.

${ }^{19}$ Nos parece importante destacar este aspecto inocente - nietzscheano, podría decirse - de la filosofía de Deleuze. Se trata de un gesto casi imperceptible, como un núcleo no-dicho que sin embargo, desde su indecibilidad, deja traslucir un compromiso amoroso e incondicional con el pensamiento. Resulta difícil, en efecto, aprehenderlo con certeza puesto que no existe, Se dirá que insiste en esa escritura luminosa, que insiste precisamente para volverla luminosa. Esa insistencia jovial, constitutiva del pensamiento deleuziano, más allá de los conceptos célebres y de las tesis comentadas hasta el hartazgo por los estudiosos, nos parece el aspecto más extraordinario de esta filosofía.

${ }^{20}$ No hay que entender aquí a la arqueología en el sentido foucaultiano, recuperado y elogiado por Deleuze, sino en su sentido etimológico, es decir como ciencia que se ocupa del origen o el principio. 
Ahora bien, es preciso no malinterpretar estos dos vectores de lectura: el retrospectivo del especialista y el prospectivo del filósofo. No por orientarse al futuro el filósofo deja de tener una relación esencial con el pasado. Es más, diríamos que posee un nexo con la memoria y la historia mucho más íntimo y profundo que el especialista. Si se interna en el pasado, si incluso hace del pasado su hábitat natural, es para hacerlo estallar y dejar que sus esquirlas atraviesen el presente y se pierdan en el futuro. La filosofía, en efecto, como la cultura en general, es impensable sin una relación con los muertos. Pero no se trata de duelo sino de necromancia. El filósofo consulta a los muertos, se deja hablar por ellos a fin de que esa voz póstuma, en una paradoja inherente al pensamiento, abra un futuro posible. Este impulso hacia el pasado, a diferencia del especialista, no obedece a una veneración insípida por la Antigüedad - con lo que esconde esa veneración de reaccionario y de insoportable -, sino una relación amorosa con el pensamiento. ¿Para qué viaja el filósofo al pasado?, ¿para qué estudia con tanta pasión las filosofías más distantes y los pensamientos más exóticos? Para encontrar excusas. El filósofo no deja de buscar excusas que le permitan pensar. ¡Qué diferencia con el especialista! Éste viaja al pasado para encontrar los certificados que le permitan erigirse en juez del conocimiento. Su única motivación pareciera ser la lucha por el reconocimiento y el puro prestigio. Der Mensch ist Anerkennen, según la famosa fórmula que Alexandre Kojève retoma de Hegel. Pero justamente por eso, cada vez que alguien deviene-filósofo se sustrae inexorablemente a su forma humana. ${ }^{21} \mathrm{El}$ filósofo no tiene tiempo - en tanto filósofo y no en tanto persona, desde luego - para el reconocimiento que lo vuelve humano: ama demasiado a los muertos, los ama demasiado como para no traicionarlos. Y como sucede con aquellas cosas que son decisivas, ese amor no puede sino conducir a l'égarement de celui qui connaît.

\footnotetext{
${ }^{21}$ ¿Acaso no identifica Deleuze a la filosofía y a la escritura en general con una multiplicidad de devenires cuyo denominador común es precisamente la pérdida de la forma humana? El primer ensayo de Critique et clinique es, en este sentido, contundente: "La escritura es inseparable del devenir; escribiendo, se deviene-mujer, se deviene-animal o vegetal, se deviene-molécula hasta devenir-imperceptible. [...] El devenir no funciona en el otro sentido, no se deviene Hombre, en tanto que el hombre se presenta como una forma de expresión dominante que pretende imponerse a cualquier materia, mientras que mujer, animal o molécula contienen siempre un componente de fuga que se sustrae a su propia formalización" (1993, p. 11).
} 


\section{Conclusión}

Como se sabe, en la famosa tesis IX de Über den Begriff der Geschichte Walter Benjamin describe un cuadro de Paul Klee que se titula Angelus Norus. En él se ve un ángel con los ojos desorbitados y la boca abierta. Mira hacia atrás: "Su rostro está vuelto hacia el pasado [Vergangenheit]" (1974, p. 697). Sin embargo, aunque sus ojos se demoran en las ruinas de lo que ha sido, un viento infla sus alas y lo impulsa hacia adelante, hacia lo que será. Este viento - que, aclara Benjamin, sopla desde el Paraíso - "lo arrastra irresistiblemente hacia el futuro [Zukunff], al cual vuelve la espalda” (1974, p. 698).

No sería osado interpretar esta figura, a la luz de lo que hemos desarrollado hasta aquí, como una alegoría de las dos lecturas señaladas previamente, la retrospectiva del especialista y la prospectiva del filósofo. El ángel, en su faceta de especialista, mira hacia atrás intentando detenerse y recomponer lo destruido (las profanaciones perpetradas a los "próceres" de la filosofía). No obstante, un viento huracanado - la filosofía - lo impulsa hacia adelante. ${ }^{22}$ Este viento que arremolina las alas del ángel, en su faceta de filósofo, es lo propio del pensamiento. Entre estas dos fuerzas se debate hoy el ángel de la filosofía y de la historia: la fuerza del pasado y la del futuro, el rostro y las alas. Tiene el rostro vuelto hacia las profundidades del pasado y las alas arremolinadas hacia el porvenir; clava su mirada espantada en las ruinas de lo que ha sido mientras sus alas lo impulsan hacia el horizonte de lo que será. El viento del pensamiento parece espantar al ángel de la historia pero alegrar al de la filosofía, las ruinas del pasado - no las ruinas de Benjamin, entiéndase, sino los monumentos solemnes e inmaculados - parecen en cambio espantar al ángel de la filosofía y alegrar al ángel de la historia. En su doble movimiento, retrospectivo y prospectivo, el ángel de la historia se vuelve por un instante inescindible del ángel de la filosofía, la filosofía de la historia no se distingue ya de la historia de la filosofía. Es probable que recién

\footnotetext{
${ }^{22}$ Recuérdese que Deleuze sostenía que la filosofía de Spinoza "sólo es comparable al viento" (2003, p. 175); y también, con un sentido ya mucho más cercano al uso de la alegoría benjaminiana que proponemos aquí: "es él [Spinoza] el que más me ha dado la impresión de ser una corriente de aire que te empuja por la espalda [un courant d'air qui vous pousse dans le dos] cada vez que lo lees, como una escoba de bruja sobre la que te hace cabalgar" (1996, p. 22).
} 
entonces, en el fulgor de ese instante, de ese tiempo propicio (kairos), pueda comenzar el único pensamiento que realmente vale la pena.

\section{Bibliografía}

BENJAMIN, W. Gesammelte Schriften - Band I: Abhandlungen. 3 Teilbände, Hrsg. von Hermann Schweppenhäuser und Rolf Tiedemann. Frankfurt am Main: Suhrkamp, 1974.

CHARTIER, R.; CAVALLO, G. Histoire de la lectura dans le monde occidental. Paris: Éditions du Seuil, 1997.

DELEUZE, G. Nietssche et la philosophie. Paris: P.U.F., 1962.

DELEUZE, G. Proust et les signes. Paris: P.U.F., 1964.

DELEUZE, G. Logique du sens. Paris: Éditions de Minuit, 1969.

DELEUZE, G. Le Pli. Leibniz et le baroque. Paris: Éditions de Minuit, 1988.

DELEUZE, G. Pourparlers. 1972-1990. Paris: Éditions de Minuit, 1990.

DELEUZE, G. Critique et clinique. Paris: Éditions de Minuit, 1993.

DELEUZE, G. Spinoza. Philosophie pratique. Paris: Éditions de Minuit, 2003.

DELEUZE, G. Foucault. Paris: Éditions de Minuit, 2004.

DELEUZE, G.; GUATTARI, F. L'Anti-CEdipe. Paris: Éditions de Minuit, 1972.

DELEuZE, G.; GUATTARI, F. Kafka. Pour une littérature mineure. Paris: Éditions de Minuit, 1975.

DeleUZE, G.; GUATTARI, F. Mille Plateaux. Paris: Éditions de Minuit, 1980.

DELEUZE, G.; GUATTARI, F. Qu'est-ce que la philosophie? Paris: Éditions de Minuit, 2005.

DELEUZE, G.; PARNET, C. Dialogues. Paris: Flammarion, 1996.

ESPOSITO, R. Terza persona. Politica della vita e filosofia dell'impersonale. Torino: Einaudi, 2007.

FOUCAULT, M. L'archéologie du savoir. Paris: Gallimard, 1969.

FOUCAULT, M. Histoire de la sexualité II - L'usage des plaisirs. Paris: Gallimard, 1984.

FOUCAULT, M. Dits et écrits. Tome II (1970-1975). Paris: Gallimard, 1994.

GUÉNON, R. Le règne de la quantité et les signes des temps. Paris: Gallimard, 1945.

HADOT, P. Qu'est-ce que la philosophie antique?. París: Gallimard, 1995. 
HEIDEGGER, M. Sein und Zeit. Frankfurt am Main: Vittorio Klostermann, 1977.

MENGUE, P. Gilles Deleuze ou le système du multiple. Paris: Éditions Kimé, 1994.

NIETZSCHE, F. Digitale Kritische Gesamtausgabe Werke und Briefe [eKGWB]. En línea: http://www.nietzschesource.org/\#eKGWB. Consultado en: 01 ene. 2019.

ORWELL, G. Nineteen Eighty-Four. London: Secker \& Warburg, 1949.

SARTRE, J.-P. El existencialismo es un humanismo. Buenos Aires: Sur, 1980.

WILLIAMS, J. Gilles Deleuze's Difference and Repetition. A Critical Introduction and Guide. Edimburgh: Edimburgh University Press, 2003.

RECEBIDO: $23 / 01 / 2019$

RECEIVED: 01/23/2019

APROVADO: 01/10/2020

APPROVED: $10 / 01 / 2020$ 